\title{
ArTí́cUlo
}

\section{Condiciones ambientales durante un florecimiento de Cochlodinium polykrikoides (Gymnodiniales, Dinophyceae) en la Ensenada de La Paz, Golfo de California}

Environmental conditions during a bloom of Cochlodinium polykrikoides

(Gymnodiniales, Dinophyceae) in Ensenada de La Paz, Gulf of California

\author{
David J. López-Cortés ${ }^{1}$, Christine J. Band-Schmidt ${ }^{2}$, José J. \\ Bustillos-Guzmán ${ }^{1}$, Francisco E. Hernández-Sandoval ${ }^{1}$, \\ Armando Mendoza-Flores ${ }^{2}$ y Erick J. Núñez-Vázquez ${ }^{1,3}$
}

\begin{abstract}
${ }^{1}$ Centro de Investigaciones Biológicas del Noroeste, S.C. (CIBNOR), Instituto Politécnico Nacional 195, Col. Playa Palo de Santa Rita, La Paz, B.C.S. 23096, México. dlopez04@cibnor.mx

${ }^{2}$ Centro Interdisciplinario de Ciencias Marinas (CICIMAR-IPN), Av. Instituto Politécnico Nacional s/n, Col. Playa Palo de Santa Rita, La Paz, B.C.S. 23096, México

${ }^{3}$ Investigación para la Conservación y el Desarrollo A. C. (INCODE), Andador 2 \#245. Col. Banobras, La Paz, B.C.S. 23080, México
\end{abstract}

\begin{abstract}
Environmental conditions are described during a bloom of Cochlodinium polykrikoides that occurred between September $12^{\text {th }}$ and November $9^{\text {th }}$ 2012, in Ensenada de La Paz, Gulf of California. At the beginning of the bloom, the number of cells, chlorophyll $a$, and peridinin was $6.2 \times 10^{2}$ cells mL $\mathrm{mL}^{-1}, 10.1 \mathrm{mg} \mathrm{m}^{-3}$, and $3.5 \mathrm{mg} \mathrm{m}^{-3}$, respectively; $8.6 \times 10^{3} \mathrm{cells}^{-1}$, $121.2 \mathrm{mg} \mathrm{m}^{-3}$ and $40.2 \mathrm{mg} \mathrm{m}^{-3}$ in their maximum intensity; and 5 cells mL ${ }^{-1}, 1.02 \mathrm{mg} \mathrm{m}^{-3}$ of chlorophyll $a$, and $0.03 \mathrm{mg} \mathrm{m}^{-3}$ of peridinin, at the end of the bloom period. Thermal interval fluctuated between 30.3 and $31.3{ }^{\circ} \mathrm{C}$; salinity varied from 35.2 to 36.8 ; dissolved $\mathrm{O}_{2}$ ranged from 4.8 to $10.8 \mathrm{~mL} \mathrm{~L}^{-1}$; saturation percentage was $>200$. The values of nitrate, phosphate, and the $\mathrm{N}: \mathrm{P}$ ratio at the initiation of the bloom were $1.8,0.9(\mu \mathrm{M})$ and 2.8 , during the maximum intensity they were $8.5,3.4(\mu \mathrm{M})$, and 2.9. At the end of the bloom they were 5.3, $0.6(\mu \mathrm{M})$ and 9.0. Prevailing winds were from the NNE (0.4-5.0 $\left.\mathrm{m} \mathrm{s}^{-1}\right)$, and a precipitation of $68 \mathrm{~mm}$ was registered previous to the bloom event. As winds diminished $<1.3 \mathrm{~m} \mathrm{~s}^{-1}$ on to SSE direction, the blooming got more intense. According to this information, we concluded that the NNE winds and continental runoff caused by rain fertilized Ensenada de La Paz waters, created conditions to support growth and survival of $C$. polykrikoides. Mortality of marine organisms was not observed during this event.
\end{abstract}

Key words: Cochlodinium polykrikoides, bloom, Gulf of California

Resumen.- Se describen las condiciones ambientales durante un florecimiento de Cochlodinium polykrikoides ocurrido desde el 12 de septiembre al 09 de noviembre 2012 en la Ensenada de La Paz, Golfo de California. Al inicio del florecimiento, el número de células, clorofila $a$ y peridinina fue de $6,2 \times 10^{2}$ cél $\mathrm{mL}^{-1}, 10,1 \mathrm{mg} \mathrm{m}^{-3}$, y $3,5 \mathrm{mg} \mathrm{m}^{-3}$ respectivamente; en su máxima intensidad de $8,6 \times 10^{3}$ cél $\mathrm{mL}^{-1}, 121,2 \mathrm{mg} \mathrm{m}^{-3}$ y $40,2 \mathrm{mg} \mathrm{m}^{-3}$ y al declinar, los valores fueron de 5 cél $\mathrm{mL}^{-1}, 1,02 \mathrm{mg} \mathrm{m}^{-3}$ de clorofila $a$ y $0,03 \mathrm{mg} \mathrm{m}^{-3}$ de peridinina. El intervalo térmico fue de $30,3-31,3^{\circ} \mathrm{C}$, la salinidad de $35,2-36,8$, el oxígeno disuelto de 4,8-10,8 $\mathrm{mL} \mathrm{L}^{-1}$ y su porcentaje de saturación $>200$. Los valores de nitratos y fosfatos y la relación N:P al inicio del florecimiento fueron de $1,8,0,9(\mu \mathrm{M})$ y 2,8 ; en su máxima intensidad de $8,5,3,4(\mu \mathrm{M})$ y 2,9 y al final de $5,3,0,6(\mu \mathrm{M})$ y 9,0 . Los vientos dominantes fueron del NNE $\left(0,4-5,0 \mathrm{~m} \mathrm{~s}^{-1}\right)$ y lluvias intensas $(68 \mathrm{~mm})$ antes del florecimiento. Al disminuir los vientos a $<1,3 \mathrm{~m} \mathrm{~s}^{-1}$ con dirección SSE, la proliferación fue más intensa. De acuerdo a toda la información obtenida, se concluye que los vientos del NNE y los arrastres continentales causados por la precipitación fertilizaron las aguas de la Ensenada de La Paz, generando condiciones para sustentar la proliferación y permanencia de C. polykrikoides. Durante el evento no se observó mortandad de organismos marinos.

Palabras clave: Cochlodinium polykrikoides, florecimiento, Golfo de California 


\section{INTRODUCCIÓN}

Cochlodinium polykrikoides Margalef es un dinoflagelado desnudo que ha formado diversos florecimientos algales particularmente en regiones tropicales, subtropicales y templadas (Gárate-Lizárraga et al. 2004, Azanza et al. 2008, Kudela \& Gobler 2012, Gobler et al. 2012). Los florecimientos de esta especie se presentan bajo una amplia ventana ambiental incluyendo la temperatura (> $\left.25^{\circ} \mathrm{C}\right)$, salinidad (25-40) y alta irradiancia sin fotoinhibición (Kudela \& Gobler 2012). Poseen gran capacidad de migración vertical y forman quistes. Además de su amplia tolerancia a los factores ambientales, su metabolismo para la asimilación de nutrientes es complejo y poseen una extensa flexibilidad en su estrategia para adquirir nutrientes. Al respecto, se ha demostrado que su tasa de crecimiento durante alimentación mixotrófica es mayor $\left(0,324 \mathrm{~d}^{-1}\right)$ que en condiciones de fotoautotrofía $\left(0,166 \mathrm{~d}^{-}\right.$ $\left.{ }^{1}\right)$ (Jeong et al. 2004). Se sugiere entonces que la mixotrofía es una estrategia que favorece sus florecimientos (Kudela et al. 2008, Kudela \& Gobler 2012), además de utilizar otros compuestos orgánicos como fuente de nitrógeno (Jeong et al. 2004, Kudela et al. 2008, Tomas \& Smayda 2008, Mulholland et al. 2009, Kudela \& Gobler 2012).

Esta especie tiene una gran capacidad de migración vertical y tolerancia a intervalos amplios de irradiancia, por lo que comúnmente sus florecimientos se observan al medio día, en la superficie de la columna de agua, aumentando su actividad fotosintética y por la noche migran al fondo marino para acceder a la nutriclina (Kudela et al. 2008, Morse et al. 2011, Kudela \& Gobler 2012). Las proliferaciones de C. polykrikoides también se han asociado a factores como la disminución en la actividad del pastoreo, a los efectos de alelopatía hacia otras especies de fitoplancton, a la eutrofización natural por escurrimientos, lluvias y actividad antropogénica (Kudela \& Gobler 2012). Aunque no es concluyente, su presencia/ proliferación se relaciona con ambientes con baja carga de nutrientes (Tomas \& Smayda 2008, Kudela et al. 2008, Morse et al. 2011). Puede ser una especie inocua, sin embargo, Kudela \& Gobler (2012) indican que durante sus florecimientos pueden provocar deterioro y mortalidad en diversos organismos, particularmente en peces de cultivo (Gárate-Lizárraga et al. 2004). Cuando C. polykrikoides se pone en contacto con sus lamelas branquiales ocasiona una hiperplasia epitelial (Gobler et al. 2008, Mulholland et al. 2009, Dorantes-Aranda et al. 2010), causando su muerte y pérdidas económicas significativas en la industria acuícola, principalmente en los países asiáticos (Kim et al. 1999a). Su toxicidad se relaciona con agentes citotóxicos (Kim et al. 1999b, 2002), neurotóxicos y hemolíticos, que pueden ser cadenas largas de ácidos grasos poliinsaturados (18:5 n3, 22:6 n3) (Kim et al. 2001, Dorantes-Aranda et al. 2009, 2010), así como sustancias reactivas de oxígeno (ROS) (Kim et al. 1999b). Los compuestos responsables de su toxicidad no han sido completamente confirmados, sin embargo ésta varía entre cepas y aún no se ha documentado en la literatura especializada que afecte al humano (Kudela \& Gobler 2012).

En el Pacífico mexicano, principalmente en los litorales de Colima, Nayarit, Jalisco y en la Bahía y Ensenada de La Paz (Golfo de California), se han registrado varios florecimientos de C. polykrikoides (Tabla 1) asociados a cambios térmicos en la columna de agua (Morales-Blake et al. 2001) y al incremento de nutrientes por arrastre de lluvias (Gárate-Lizárraga et al. 2004, Gárate-Lizárraga 2013). Únicamente en 3 casos su presencia se ha relacionado con la mortandad de peces (Gárate-Lizárraga et al. 2000, 2004; Gómez-Villarreal et al. 2008). En este trabajo se describen las condiciones ambientales prevalecientes durante el florecimiento de C. polykrikoides, con el propósito de contribuir al conocimiento de su ecología en esta región.

\section{MATERIALES Y MÉTODOS}

\section{ZONA DE ESTUDIO}

La Ensenada de La Paz es una laguna costera ubicada en la parte sur de la Bahía de La Paz (2414'N, 110 29'O), Golfo de California (Lechuga-Devéze et al. 1986). Alcanza un área de $45 \mathrm{~km}^{2}$, las profundidades promedio van de $2 \mathrm{a}$ $4 \mathrm{~m}$ en más del $50 \%$ de la laguna y el intercambio de agua con la Bahía de La Paz es a través de un canal de mareas de $8 \mathrm{~m}$ de profundidad (Cervantes-Duarte et al. 2001). El clima de la región es semidesértico, la evaporación (300 $\mathrm{mm}$ año $\left.{ }^{-1}\right)$ excede la escasa precipitación $\left(180 \mathrm{~mm}\right.$ año $\left.{ }^{-1}\right)$ (Jiménez-Illescas et al. 1997) (Fig. 1).

\section{MuestReO}

En 2 estaciones (E-1: presencia del florecimiento, E-2: fuera del ámbito del florecimiento), ubicadas en la parte más interna de esta laguna costera y con una profundidad de $3 \mathrm{~m}$ (Fig. 1), se hicieron recorridos en la embarcación para detectar una posible mortandad de peces. También se recolectaron muestras superficiales de fitoplancton con botellas de $1 \mathrm{~L}$, las que se fijaron con una solución de lugol ácido y/o paraformaldehído al 1\% (Katano et al. 2009) para conteo y clasificación taxonómica de la especie 
Tabla 1. Florecimientos de C. polykrikoides en las costas del Pacífico Este y otras regiones del mundo / Blooms of $C$. polykrikoides in the East Pacific coast and other world regions

\begin{tabular}{|c|c|c|c|c|}
\hline & $\begin{array}{c}\text { Temperatura } \\
\left({ }^{\circ} \mathrm{C}\right)\end{array}$ & $\begin{array}{l}\text { C. polykrikoides } \\
\quad\left(\text { cél } \mathrm{mL}^{-1}\right)\end{array}$ & Fecha & Referencia \\
\hline \multicolumn{5}{|l|}{ Región: Pacífico Este } \\
\hline Bahía de Manzanillo, Colima & $25,5-21,2$ & 3258 & Feb-Abr/2000 & Morales-Blake et al. 2001 \\
\hline Bahía de La Paz, Golfo de California & $29,0-31,0$ & $360-7050$ & $15-28 / \mathrm{Sep} / 2000$ & Gárate-Lizárraga et al. 2004 \\
\hline Costa Pacifico, Costa Rica & $\mathrm{Nd}$ & 120 y $170,175000,380000$ & May/2002, Oct/2003, Abr/2004 & Vargas-Montero et al. 2004, 2006 \\
\hline Bahía de Banderas, Nayarit & $\mathrm{Nd}$ & 1200 & May/2000 & Gómez-Villarreal et al. 2008 \\
\hline Bahía de La Paz, Golfo de California & $20,0-26,0$ & 58,2 y 65,0 & Abr-Jun/2006 & Gárate-Lizárraga \& Muñeton 2008 \\
\hline Ensenada y Bahía de La Paz, Golfo de California & $29,0-30,0$ & 73 a 1425 & 16 y $17 / \mathrm{Ago} / 2012$ & Gárate-Lizárraga 2013 \\
\hline Costa Pacífico, El Salvador & $26,8-28,7$ & 215000 & 23/Mar/2012 & Espinoza et al. 2013 \\
\hline Bahía de Monterey, CA, E.U.A. & $14-18$ & $120-200$ & Ago-Sep/2004, 2006 & Kudela et al. 2008 \\
\hline Ensenada de La Paz, Golfo de California & $30,3-31,3$ & $\sim 2699-8600$ & Sep-Oct $/ 2012$ & Este trabajo \\
\hline \multicolumn{5}{|l|}{ Otras regiones: } \\
\hline Estuario Peconic en Long Island, E.U.A. & $\mathrm{Nd}$ & 2000 & Sep-Oct/2004 & Nuzzi 2004 \\
\hline Palawan, Filipinas & $31,0-36,0$ & 2613 a 3022 & Mar-Abr/2005 & Azanza et al. 2008 \\
\hline Pettaquamscutt Cove, Rhode Island, E.U.A. & 19,0 y 28,0 & $>1000$ & Jul-Ago/1981 & Tomas \& Smayda 2008 \\
\hline Sabah,Malasia & $30,1-31,2$ & 4160 & Mar,May, Jun/2005 & Anton et al. 2008 \\
\hline Great Peconic Bay, E.U.A. & 25,0 & $>10000 \mathrm{y}>100000$ & Ago/2006 & Gobler et al. 2008 \\
\hline Bahía de Chesapeake, MD, E.U.A. & $27,0-29,5$ & 11137 & 11/Ago, 6/Sep/2007 & Mulholland et al. 2009 \\
\hline Este, Mar de China & 23,7 & 42 & $14 / \mathrm{Sep} / 2006$ & Matsuoka et al. 2010 \\
\hline Golfo de Arabia & 27,0 & $11000-21000$ & Oct $/ 2008$ & Richlen et al. 2010 \\
\hline Lower Chesapeake Bay-Tributaries, E.U.A. & $26,6-29,6$ & 115000 & 29/Ago/2008 & Morse et al. 2011 \\
\hline Estuarios de Nueva York, E.U.A. & $24,2 \pm 0,5$ & $6890 \pm 2980$ & Ago-Sep/2006,2008 & Gobler et al. 2012 \\
\hline Bahía de Santa Marta, Colombia-Caribe & $28,0-32,0$ & 5000 & Oct $/ 2010,2011$ & Malagon \& Perdomo 2013 \\
\hline
\end{tabular}

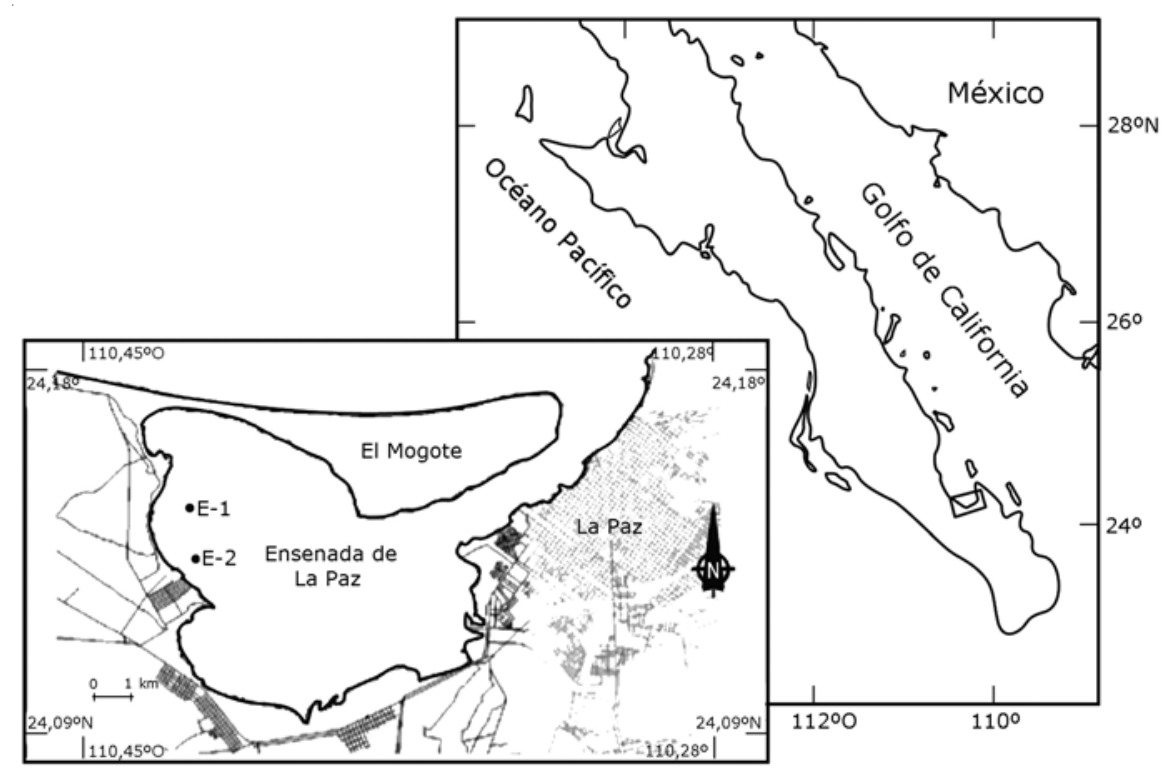

Figura 1. Ubicación de la zona de estudio. Estación E-1 y E-2, dentro y fuera del florecimiento de $C$. polykrikoides respectivamente, ocurrido desde sep/12 a nov/09 de 2012, en la Ensenada de La Paz, B.C.S. México / Location of the study zone. Station E-1 and E-2 are located inside and outside respectively of a bloom of $C$. polykrikoides that occurred in Ensenada de La Paz, B.C.S., México from Sep/12 to Nov/09 2012 
dominante, basada en Margalef(1961), Fukuyo et al. (1990) y Steidinger \& Tangen (1996). Las muestras extraídas del florecimiento se depositaron en frascos de $2 \mathrm{~L}$, sin fijar, para su identificación taxonómica y minutos antes de su clasificación las células vivas fueron inmovilizadas con paraformaldehído al 1\%. Otra muestra del florecimiento fue depositada en frascos Falcon de $250 \mathrm{~mL}$, conteniendo $50 \mathrm{~mL}$ de medio de cultivo GSe (Blackburn et al. 2001), para su aislamiento, cultivo y posterior cuantificación del contenido de pigmentos fotosintéticos, por medio del análisis de Cromatografía Líquida de Alta Resolución (HPLC).

\section{Pigmentos fotosintéticos y nUtRientes}

Se tomaron muestras de agua superficial con una botella Van Dorn; se filtró $1 \mathrm{~L}$ a través de una membrana GF/F $(0,7$ $\mu \mathrm{m}$, Whatman, Maidstone, UK). El material retenido se utilizó para identificar y cuantificar clorofila a (Clo-a), peridinina y otros pigmentos fotosintéticos con un HPLC Hewlett Packard® Mod. HP1100. La cuantificación se basó en la absorbancia a $440 \mathrm{~nm}$ y el valor del factor de respuesta de cada pigmento (concentración de pigmento/ absorbancia) de acuerdo a Vidussi et al. (1996) y Mantoura \& Repeta (1997). La identificación de los pigmentos se realizó considerando 2 criterios, al comparar el tiempo de retención y las características espectrales con estándares comerciales certificados (Internacional Agency for ${ }^{14} \mathrm{C}$ determinations, Denmark). El agua filtrada se usó para la cuantificación de $\mathrm{NO}_{3}, \mathrm{NH}_{4}, \mathrm{PO}_{4} \mathrm{y} \mathrm{Si}(\mathrm{OH})_{4}$, de acuerdo a Strickland \& Parsons (1972), usando un autoanalizador de flujo continuo de iones (Quik Chem, Series 8000, Milwaukee, WN, E.U.A.). El nitrógeno inorgánico disuelto (NID) se consideró como la suma de los compuestos nitrogenados $\left(\mathrm{NO}_{3}+\mathrm{NH}_{4}\right)$.

\section{TeMPeRATURA, SALINIDAD Y OXíGENO}

Con un multi-sensor (YSI 556 MPS-10G101448, E.U.A.), se registró la temperatura y salinidad. El oxígeno disuelto se determinó por el método de Winkler (Strickland \& Parsons 1972) y los porcentajes de saturación se calcularon según Parsons et al. (1984). Los datos de vientos y lluvia fueron adquiridos de la estación meteorológica del Centro de Investigaciones Biológicas del Noroeste, S.C. (CIBNOR).

\section{CuANTIFICACIÓN DE C. POLYKRIKOIDES EN CAMPO}

Debido a la problemática en la preservación de $C$. polykrikoides con los fijadores comunes (GárateLizárraga et al. 2004, Kudela \& Gobler 2012), se calculó la densidad de C. polykrikoides a partir de la concentración de peridinina medida en muestras de campo (BustillosGuzmán et al. 2004) y la ecuación obtenida de la relación entre el número de células de C. polykrikoides y la concentración de peridinina en condiciones de cultivo (ver abajo).

\section{Cepa de Cochlodinium}

Cochlodinium polykrikoides (cepa COPAZ-8) (Fig. 2) fue recolectada directamente del florecimiento ocurrido en octubre de 2012 y aislada bajo microscopio invertido Carl Zeiss ${ }^{\circledR}$. Las células individuales fueron transferidas a placas de ensayo de 96 pocillos, previamente llenadas con medio GSe (Blackburn et al. 2001) usando extracto de lombricompostaje y mantenidas a $24 \pm 1^{\circ} \mathrm{C}$, con una intensidad de luz de $150 \mu \mathrm{mol} \mathrm{m} \mathrm{m}^{-2} \mathrm{~s}^{-1} \mathrm{y}$ en un ciclo D:N 12:12. Los medios de cultivo se prepararon con agua de mar de la Bahía de La Paz ( 34,0 de salinidad). El agua de mar y los nutrientes se esterilizaron a través de un filtro de $0,22 \mu \mathrm{m}$ (Nalgene). Los cultivos de los pocillos fueron gradualmente transferidos a volúmenes de $50 \mathrm{~mL}$ de capacidad para su mantenimiento.

\section{RELACIÓN ENTRE PERIDININA Y NÚMERO DE CÉLULAS DE C. POLYKRIKOIDES}

Se realizó un cultivo con la cepa de C. polykrikoides (COPAZ-8) por triplicado en matraces Erlenmeyer de 250 $\mathrm{mL}$ con medio GSe, bajo las condiciones de cultivo descritas previamente. Cada segundo día, $2 \mathrm{~mL}$ de submuestra del cultivo se fijaban con una solución de paraformaldehido al 1\% (Katano et al. 2009) y posteriormente eran contados en una cámara de Sedgewick-Rafter de $1 \mathrm{~mL}$ de capacidad, bajo un microscopio óptico (Carl Zeiss ${ }^{\circledR}$ ). Para el análisis de pigmentos, cada 2 días se filtraban a través de membranas GF/F entre 5 y $20 \mathrm{~mL}$ del cultivo. Posterior a ello las muestras eran almacenadas inmediatamente a una temperatura de $-20^{\circ} \mathrm{C}$. Los pigmentos fueron analizados en un sistema HPLC de acuerdo a Vidussi et al. (1996). Una vez calculada la densidad celular y el contenido de peridinina para cada fecha de muestreo, se hizo un análisis de regresión y correlación simple entre ambos grupos de datos. La ecuación obtenida fue C. polykrikoides $=175$ [peridinina] - 1047,3 $\left(\mathrm{r}^{2}=0,90 ; \alpha=0,05\right)$ y se utilizó para extrapolar la densidad de C. polykrikoides durante el florecimiento a partir de las mediciones de peridinina. 

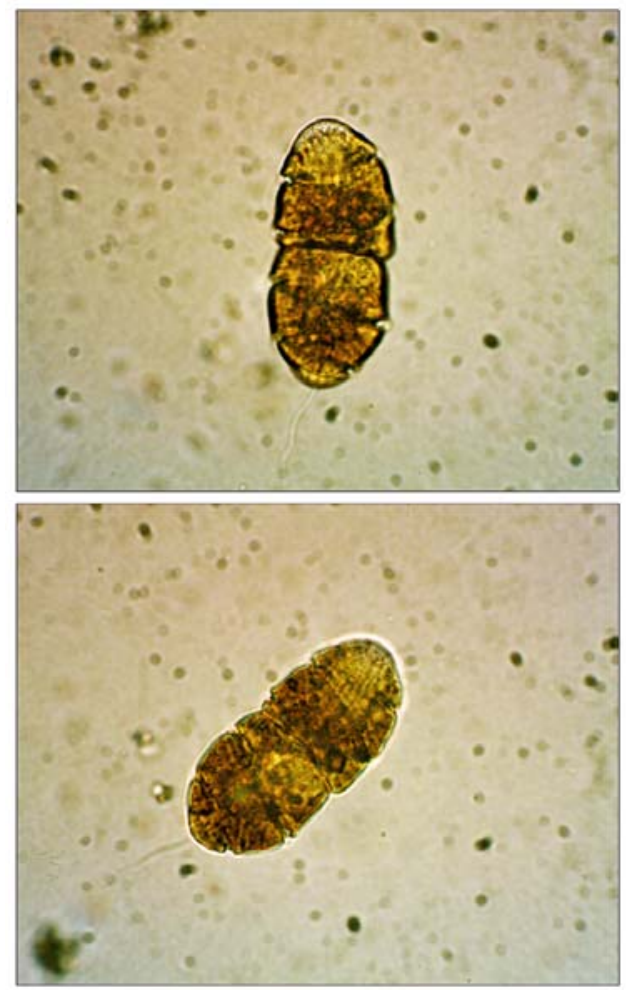

Figura 2. Imágenes obtenidas con un microscopio de luz de $C$. polykrikoides aislada de la Ensenada de La Paz, B.C.S. México (sep/12-nov/09 de 2012) (Foto: Leyberth J. Fernández Herrera) / Light microscopy images of $C$. polykrikoides isolated from Ensenada de La Paz, B.C.S. México (Sep/12 to Nov/09 2012) (Photo: Leyberth J. Fernández Herrera)

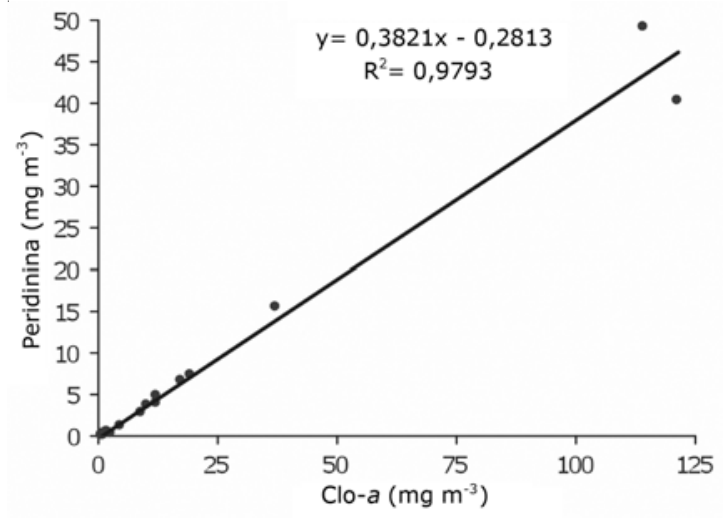

Figura 3. Correlación de Clo- $a$ y peridinina (E-1) durante un florecimiento de C. polykrikoides en la Ensenada de La Paz, B.C.S. México, desde sep/12 a nov/09 de 2012 / Correlation between $\mathrm{Chl}-a$ and peridinin (E-1) during a bloom of $C$. polykrikoides in Ensenada de La Paz, B.C.S., México from Sep/ 12 to Nov/9 2012

\section{Resultados}

\section{RECUENTO DE CÉLULAS}

Al inicio del florecimiento la densidad de C. polykrikoides fue de $\sim 6,23 \times 10^{2}$ cél $\mathrm{mL}^{-1}$. Durante la máxima intensidad esta variable osciló entre $\sim 8,6 \times 10^{3}$ y $\sim 7,05 \times 10^{3}$ cél $\mathrm{mL}^{-1}$ (01/10/2012 y 05/10/2012, respectivamente), bajando al final del florecimiento, ocurrido a comienzos de noviembre, $\mathrm{a} \sim 5$ cél $\mathrm{mL}^{-1}$. En la E-2 la abundancia fue menor a $\sim 260$ cél $\mathrm{mL}^{-1}$ durante todo el evento. En este florecimiento de $C$. polykrikoides (septiembre a noviembre de 2012) no se registró mortandad de peces (Tabla 1).

\section{Pigmentos fotosintéticos}

En la estación E-1 los valores de Clo- $a$ y peridinina al inicio del florecimiento fueron de 10,1 y $3,5 \mathrm{mg} \mathrm{m}^{-3}$, respectivamente. Durante la máxima intensidad alcanzó a $114,3 \mathrm{mg} \mathrm{m}^{-3}$ (Clo- $a$ ) y 49,0 $\mathrm{mg} \mathrm{m}^{-3}$ de peridinina (Tabla 2), siendo alta la correlación Clo- $a$ vs peridinina $\left(r^{2}=0,97 ; \alpha\right.$ $=0,05)$ (Fig. 3). En la estación E-2 los valores de Clo- $a$ fueron $<4,2 \mathrm{mg} \mathrm{m}^{-3}$, mientras que la peridinina fue $<1,4$ $\mathrm{mg} \mathrm{m}^{-3}$ (Tabla 2). En ambas estaciones además se identificaron otros pigmentos, cuyos valores máximos se registraron en la E-1 durante el florecimiento de $C$. polykrikoides, principalmente de Clo- $C\left(10,7 \mathrm{a} 31,7 \mathrm{mg} \mathrm{m}^{-3}\right)$, diadinoxantina (3,6 a 16,4 $\mathrm{mg} \mathrm{m}^{-3}$ ) y ß-caroteno (2,0 a 10,6 mg $\mathrm{m}^{-3}$ ). Los valores de Clo- $b$ y zeaxantina fueron bajos (Tabla 2) e incluso ausentes en las células cultivadas.

\section{TEMPERATURA, SALINIDAD Y OXÍGENO DISUELTO}

Durante el florecimiento ambas estaciones presentaron valores de temperatura y salinidad similares. Cuando se detectó el florecimiento la temperatura fue de $32^{\circ} \mathrm{C}$, la que fue disminuyendo paulatinamente hasta alcanzar $26,4^{\circ} \mathrm{C}$ a comienzos de noviembre. Durante la máxima intensidad del evento, el intervalo térmico varió de 30,3 a $31,3^{\circ} \mathrm{C}$ (Fig. 4). La salinidad osciló de 35,2 a 36,8, el oxígeno disuelto de 9,0 a 9,3 $\mathrm{mL} \mathrm{L}^{-1}$ y sus porcentajes de saturación fueron $>200$ (datos no presentados).

\section{LLUVIA Y VIENTO}

Durante el periodo de lluvia del año 2012, la máxima precipitación se registró a fines de septiembre $(86,2 \mathrm{~mm})$. Los primeros días de este mes, antes de la detección del florecimiento de C. polykrikoides, hubo intensas lluvias con un valor medio de precipitación de $68 \mathrm{~mm}, 9$ días después se detectó un cambio en la coloración del agua de $\operatorname{mar}\left(6,23 \times 10^{2}\right.$ cél $\mathrm{mL}^{-1}$ en E-1), con valores de Clo- $a$ y 
Tabla 2. Pigmentos fotosintéticos y número de células de muestras obtenidas durante un florecimiento de $C$. polykrikoides desde sep/12 a nov/09 de 2012 en la Ensenada de La Paz, B.C.S., Golfo de California. Clorofila $a$ (Clo$a)$, Clorofila $b$ (Clo-b), Clorofila $c$ (Clo-c), Peridinina (Peri), Diadinoxantina (Diadino), Zeaxantina (Zeax), $\beta$-Caroteno ( $\beta$-Carot) / Photosynthetic pigments and cell number of samples obtained during a bloom of $C$. polykrikoides from Sep/12 to Nov/09 2012 at Ensenada de La Paz, B.C.S., Gulf of California. Chlorophyll $a$ (Chl-a), Chlorophyll $b$ (Chl$b)$, Chlorophyll $c(\mathrm{Chl}-c)$, Peridinin (Peri), Diadinoxanthin (Diadino), Zeaxanthin (Zeax), $\beta$-Carotene ( $\beta$-Carot)

\begin{tabular}{|c|c|c|c|c|c|c|c|c|}
\hline & $\begin{array}{l}\text { Abundancia } \\
\text { (cél } \mathrm{mL}^{-1} \text { ) }\end{array}$ & Clo- $a$ & Clo- $b$ & Clo- $c$ & $\underset{\left(\mathrm{mg} \mathrm{m}^{-3}\right)}{\text { Peri }}$ & Diadino & Zeax & $\beta$-Carot \\
\hline \multicolumn{9}{|l|}{ E-1 } \\
\hline Sep-12-12 & 623,3 & 10,13 & 0,13 & 2,71 & 3,56 & 0,93 & 0,21 & 0,17 \\
\hline Sep-14-12 & 692,9 & 12,24 & 0,15 & 3,21 & 3,96 & 1,14 & 0,33 & 0,27 \\
\hline Sep-17-12 & 822,3 & 12,11 & 0,00 & 3,17 & 4,70 & 1,09 & 0,23 & 0,31 \\
\hline Sep-19-12 & 1142,1 & 17,46 & 0,00 & 5,82 & 6,52 & 1,63 & 0,23 & 0,47 \\
\hline Sep-21-12 & 46,7 & 1,32 & 0,04 & 0,27 & 0,27 & 0,10 & 0,15 & 0,07 \\
\hline Sep-24-12 & 483,3 & 9,27 & 0,00 & 2,31 & 2,76 & 0,86 & 0,23 & 0,48 \\
\hline Oct-01-12 & 2699,4 & 37,28 & 0,00 & 10,72 & 15,42 & 3,65 & 0,42 & 2,06 \\
\hline Oct-03-12 & 8600,8 & 114,34 & 0,00 & 31,74 & 49,13 & 15,44 & 0,75 & 6,46 \\
\hline Oct-05-12 & 7050,1 & 121,24 & 1,12 & 29,36 & 40,27 & 16,45 & 1,58 & 10,66 \\
\hline Oct-08-12 & 217,3 & 4,72 & 0,09 & 1,01 & 1,24 & 0,39 & 0,19 & 0,26 \\
\hline Oct-10-12 & 1255,7 & 19,59 & 0,22 & 4,88 & 7,17 & 3,14 & 0,34 & 1,95 \\
\hline Oct-12-12 & 92,0 & 2,03 & 0,09 & 0,35 & 0,53 & 0,19 & 0,21 & 0,14 \\
\hline Oct-18-12 & 49,0 & 2,80 & 0,13 & 0,17 & 0,00 & 0,42 & 0,14 & 0,08 \\
\hline Oct-22-12 & 8,6 & 0,90 & 0,00 & 0,03 & 0,05 & 0,07 & 0,07 & 0,04 \\
\hline Oct-26-12 & 6,7 & 1,17 & 0,10 & 0,04 & 0,04 & 0,09 & 0,23 & 0,07 \\
\hline Oct-31-12 & 5,8 & 0,65 & 0,05 & 0,12 & 0,03 & 0,03 & 0,17 & 0,05 \\
\hline Nov-09-12 & 5,3 & 1,02 & 0,10 & 0,03 & 0,00 & 0,03 & 0,18 & 0,06 \\
\hline \multicolumn{9}{|l|}{ E-2 } \\
\hline Sep-12-12 & 82,5 & 0,26 & 0,06 & 0,42 & 0,47 & 0,16 & 0,22 & 0,09 \\
\hline Sep-14-12 & 89,0 & 2,75 & 0,13 & 0,50 & 0,51 & 0,17 & 0,25 & 0,11 \\
\hline Sep-17-12 & 220,9 & 4,13 & 0,13 & 0,89 & 1,26 & 0,35 & 0,21 & 0,15 \\
\hline Sep-19-12 & 76,2 & 1,93 & 0,09 & 0,41 & 0,44 & 0,16 & 0,20 & 0,09 \\
\hline Sep-21-12 & 96,2 & 2,01 & 0,08 & 0,47 & 0,55 & 0,18 & 0,20 & 0,13 \\
\hline Sep-24-12 & 13,9 & 1,07 & 0,13 & 0,15 & 0,08 & 0,06 & 0,23 & 0,08 \\
\hline Oct-01-12 & 175,6 & 3,40 & 0,10 & 0,70 & 1,00 & 0,29 & 0,13 & 0,15 \\
\hline Oct-03-12 & 260,0 & 4,26 & 0,00 & 1,11 & 1,49 & 0,58 & 0,08 & 0,38 \\
\hline Oct-05-12 & 13,0 & 0,75 & 0,00 & 0,10 & 0,07 & 0,02 & 0,04 & 0,03 \\
\hline Oct-08-12 & 180,2 & 3,40 & 0,07 & 0,88 & 1,03 & 0,46 & 0,22 & 0,31 \\
\hline Oct-10-12 & 38,3 & 0,90 & 0,00 & 0,12 & 0,22 & 0,04 & 0,05 & 0,05 \\
\hline Oct-12-12 & 17,5 & 1,26 & 0,00 & 0,22 & 0,10 & 0,05 & 0,05 & 0,05 \\
\hline Oct-18-12 & 19,9 & 2,05 & 0,08 & 0,16 & 0,11 & 0,22 & 0,08 & 0,05 \\
\hline Oct-22-12 & 10,0 & 1,23 & 0,06 & 0,03 & 0,06 & 0,14 & 0,03 & 0,04 \\
\hline Oct-26-12 & 3,5 & 0,80 & 0,07 & 0,03 & 0,02 & 0,05 & 0,07 & 0,03 \\
\hline Oct-31-12 & 3,5 & 0,37 & 0,06 & 0,00 & 0,00 & 0,02 & 0,07 & 0,02 \\
\hline Nov-09-12 & 3,5 & 0,73 & 0,05 & 0,02 & 0,00 & 0,04 & 0,09 & 0,04 \\
\hline
\end{tabular}

E-1: presencia del florecimiento, E-2: fuera del ámbito del florecimiento

peridinina relativamente altos $\left(9,0-17,0\right.$ y $2,7-6,0 \mathrm{mg} \mathrm{m}^{-3}$, respectivamente) (Fig. 5). Posteriormente, transcurrida la última semana del mes, se intensificaron las lluvias, las que duraron 3 días consecutivos (136,5 mm). Al cesar la precipitación, se registró la máxima intensidad del florecimiento, reflejándose en valores altos de Clo- $a$ $\left(121,2 \mathrm{mg} \mathrm{m}^{-3}\right)$ y peridinina $\left(49,0 \mathrm{mg} \mathrm{m}^{-3}\right)$. En los días siguientes la intensidad del florecimiento fue disminuyendo paulatinamente.

Los vientos dominantes antes del florecimiento registraron una velocidad de 0,4 a $5,0 \mathrm{~m} \mathrm{~s}^{-1}$ y provenían del NNE. Durante el muestreo (medio día) prevalecieron los vientos con dirección NE y una intensidad de 0,9 a 1,8 $\mathrm{m} \mathrm{s}^{-1}$, sin embargo cuando disminuyeron a $<1,3 \mathrm{~m} \mathrm{~s}^{-1} \mathrm{y}$ mostraron una dirección SE, el florecimiento se intensificó (Figs. $6 \mathrm{a}, \mathrm{b}, \mathrm{c}$ ). Al final de este evento los vientos fueron de $0,9 \mathrm{~m} \mathrm{~s}^{-1} \mathrm{O}$ y de $1,8 \mathrm{~m} \mathrm{~s}^{-1} \mathrm{SE}$.

\section{NUTRIENTES INORGÁNICOS}

La concentración de nutrientes en la estación E-1 al inicio del florecimiento fue menor a $1,8 \mu \mathrm{M}$. En la máxima densidad celular y después de intensas lluvias hubo 


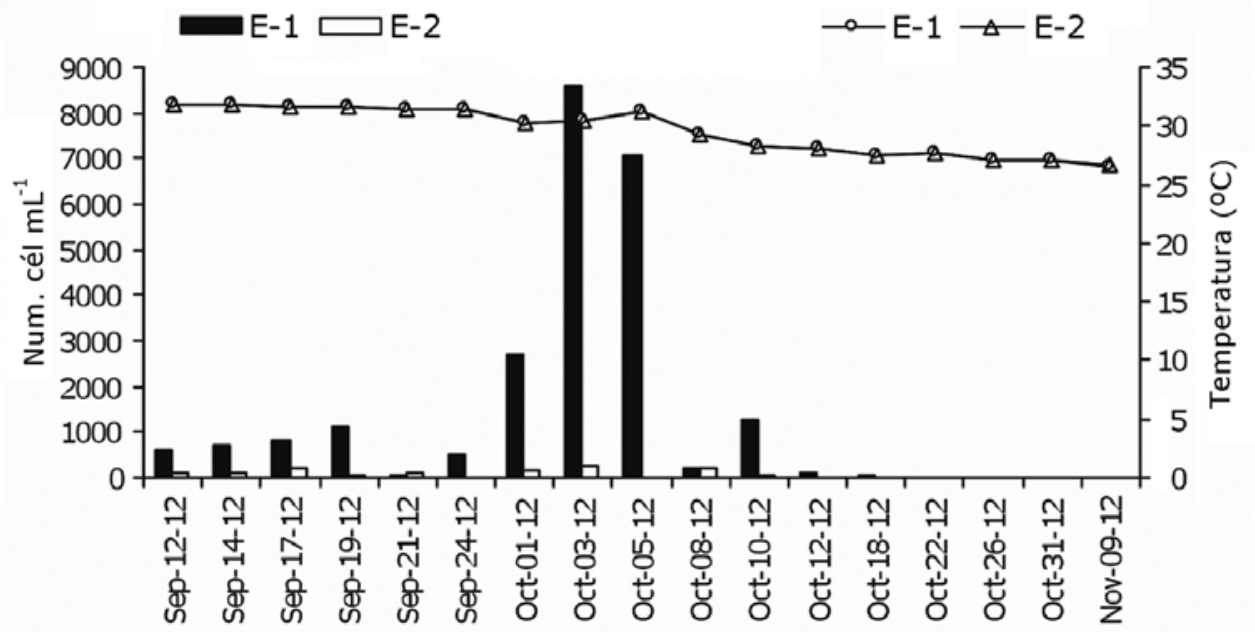

Figura 4. Número de células estimadas (barras negras y blancas) y valores de temperatura superficial del mar (líneas con círculos y triángulos), durante un florecimiento de $C$. polykrikoides en la Ensenada de La Paz, B.C.S, México, desde sep/12 a nov/09 2012 / Cell number estimations (black and white bars) and sea surface temperature (lines with circles and triangles), during a bloom of $C$. polykrikoides in Ensenada de La Paz, B.C.S. México from Sep/12 to Nov/09 2012

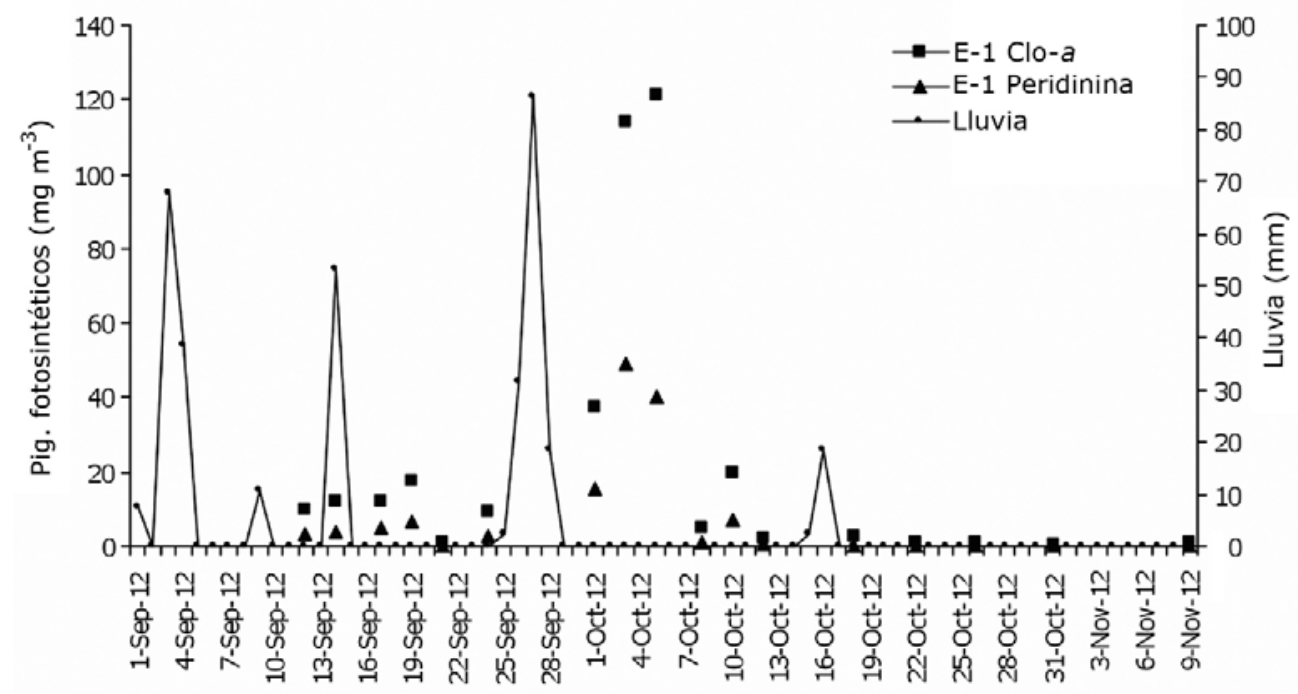

Figura 5. Precipitación pluvial y variación de la biomasa de clorofila $a$ y peridinina, durante un florecimiento de C. polykrikoides en la Ensenada de La Paz, B.C.S. México, desde sep/12 a nov/09 2012 / Rain precipitation and biomass of chlorophyll $a$, and peridinin variation during a bloom of $C$. polykrikoides in Ensenada de La Paz, B.C.S., México from Sep/12 to Nov/09 2012 
a) Frecuencia de dirección del viento (\%)
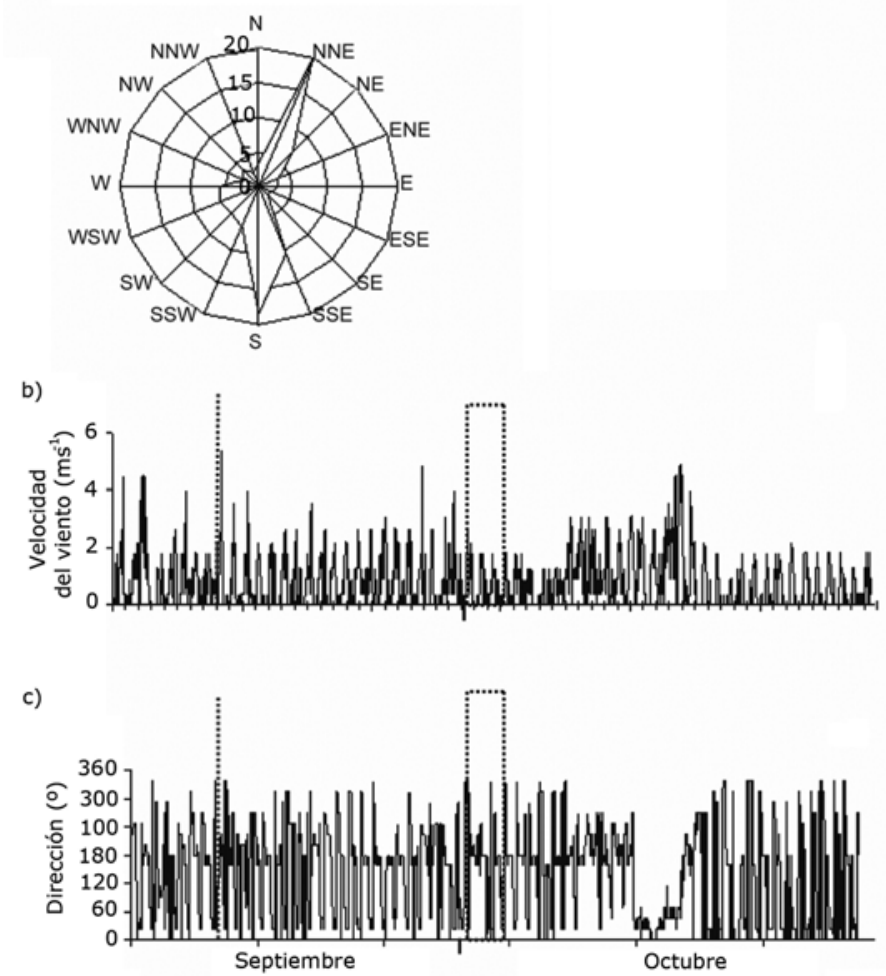

Figura 6. Porcentaje de dominancia (a), velocidad (b) y dirección (c) del viento desde sep/12 a nov/09 2012 en la Ensenada de La Paz, B.C.S, México. Línea vertical punteada: detección del florecimiento (sep/12/2012); Rectángulo punteado: máxima densidad del florecimiento (oct/01,03,05/2012) / Percentage of dominance (a) wind speed (b) and wind direction (c) during a bloom of $C$. polykrikoides in Ensenada de La Paz, B.C.S., México from Sep/12 to Nov/09 2012- Dotted vertical line: bloom detection (Sep/12/2012); Dotted rectangle: maximum density during the bloom (Oct/01,03,05/2012)

incremento, principalmente de nitratos y fosfatos, sin embargo en la E-2 los valores fueron bajos desde el inicio hasta el final del evento (Fig. 7). Los intervalos del $\mathrm{Si}(\mathrm{OH})_{4}$ se registraron desde 9,0 a $34,9 \mu \mathrm{M}$ en ambas estaciones (datos no graficados).

\section{ReLación N:P}

Al inicio del florecimiento y durante la máxima abundancia de células de $C$. polykrikoides, clorofila- $a$, y peridinina, la razón N:P (molecular) del NID:PID fue baja en la estación E-1 $(<3)$, lo que sugiere que su proliferación ocurre en condiciones ambientales altas en fosfatos y relativamente bajas de nitrógeno (Fig. 8). En esta figura se observa que en los últimos días del evento hubo un incremento de este cociente, no obstante su proliferación no prosperó.

\section{Discusión}

En este trabajo se reporta un florecimiento de $C$. polykrikoides en la Ensenada de La Paz asociado primero a lluvias y vientos del NNE, los que contribuyeron a la fertilización de la columna de agua. Posteriormente vientos del SSE de menor intensidad ocasionaron la estabilidad de la columna de agua, propiciando un ambiente adecuado para la proliferación de esta especie. Condiciones similares han sido registradas durante los florecimientos previos de C. polykrikoides en la misma zona (Gárate-Lizárraga et al. 2000, 2004; Gárate-Lizárraga 2013). En las costas de Malasia (Anton et al. 2008), Filipinas (Azanza et al. 2008) y Estados Unidos (Mulholland et al. 2009, Morse et al. 2011, 2013) los florecimientos de esta especie también han sido vinculados a la fertilización por efecto de la lluvia y los vientos. De acuerdo con estos autores estas 2 variables influyen significativamente en los florecimientos de este dinoflagelado. 

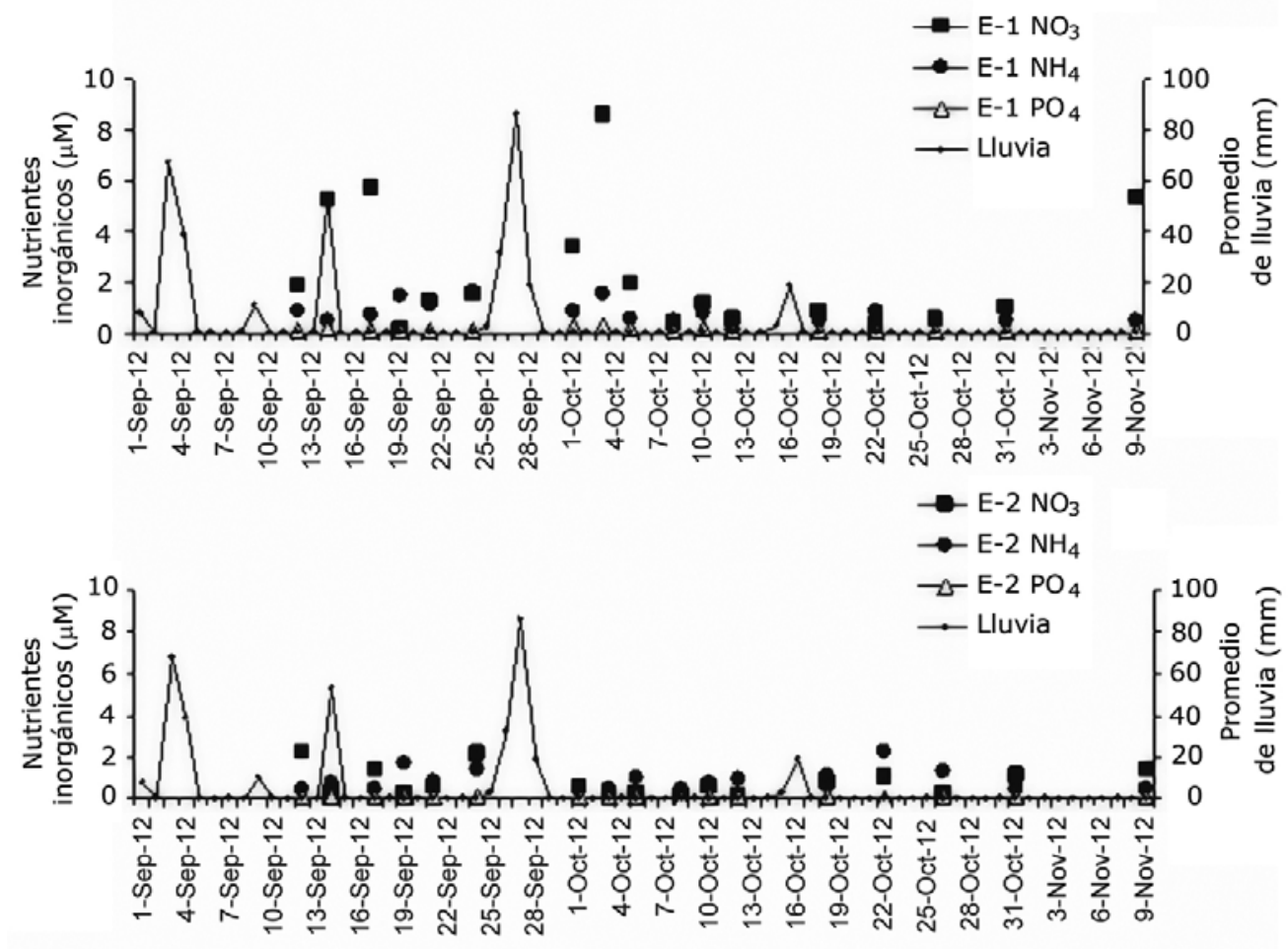

Figura 7. Variación de nutrientes inorgánicos y precipitación pluvial durante un florecimiento de $C$. polykrikoides en la Ensenada de La Paz, B.C.S. México, sep/12-nov/09 2012 (Estaciones E-1 y E-2) / Variation of inorganic nutrients and rainfall during a bloom of C. polykrikoides in Ensenada de La Paz, B.C.S., México, Sep/12 to Nov/09 2012 (Stations E-1 and E-2)

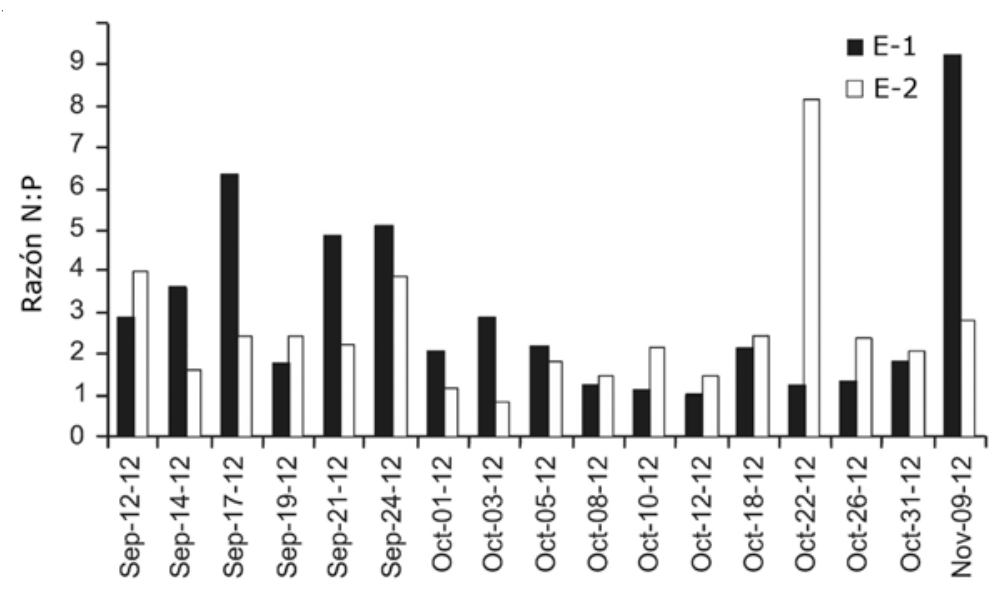

Figura 8. Variación de la razón N:P durante el florecimiento de C. polykrikoides en la Ensenada de La Paz, B.C.S. México, sep/12-nov/09 2012 (Estaciones E-1 y E-2) / Variation of N:P ratio during a bloom of $C$. polykrikoides in Ensenada de La Paz, B.C.S., México, Sep/12 to Nov/09 2012 (Stations E-1 and E-2) 
Durante las proliferaciones de C. polykrikoides generalmente se utilizan soluciones de acetato lugol y/o formaldehído para conservar las células, sin embargo, estos fijadores pueden destruirlas e imposibilitar su identificación (Gárate-Lizárraga et al. 2004, Kudela \& Gobler 2012). Es por ello que Gárate-Lizárraga (2013) recomienda el uso de muestras vivas para la identificación de esta especie. Lo anterior justifica claramente el uso de la peridinina como una alternativa para calcular la densidad del dinoflagelado (Bustillos-Guzmán et al. 2004). Es claro que dicho método puede incluir otras células que contengan peridinina, sin embargo la alta correlación con la clorofila $a$ y la baja densidad de otros dinoflagelados (Gárate-Lizárraga 2013) sugieren que C. polykrikoides es el principal aporte del pigmento durante este florecimiento. Esta especie ya ha sido registrada en la Bahía de La Paz (Gárate-Lizárraga et al. 2001, 2004; GárateLizárraga \& Munetón-Gómez 2008, Gárate-Lizárraga 2013); en el año 2000 fue asociada a una mortandad de peces en cautiverio en la Ensenada de La Paz (Gárate-Lizárraga et al. 2004). Aún cuando en este trabajo no se registró mortandad de peces, no se descarta su probable toxicidad, ya que en una cepa de C. polykrikoides aislada de la Bahía de La Paz, Dorantes-Aranda et al. (2010) registraron su efecto ictiotóxico en el pez Lutjanus guttatus (Steindachner), causándole pérdida de balance, dificultad para respirar, estrés oxidativo en las lamelas branquiales, producción anormal de mucus y muerte por asfixia.

Durante un florecimiento en Pattaquamscutt Cove (Rhode Island, Estados Unidos), Tomas \& Smayda (2008) mencionan que las cadenas o células aisladas al depositarse en botellas experimentales forman masas gelatinosas, que se precipitan en el fondo de los recipientes. La formación de estos conglomerados gelatinosos de C. polykrikoides también se observó en este trabajo y sólo algunas células logran sobrevivir por corto tiempo, dificultando aún más los conteos. Además cuando a las muestras se les adicionó lugol, las células se destruyeron. Al respecto Gárate-Lizárraga et al. (2004) y Kudela \& Glober (2012) mencionan que la fijación dificulta la identificación y los conteos, por lo que recomiendan técnicas moleculares para lograr una cuantificación e identificación más precisa. Sin embargo, Gárate-Lizárraga (2013) documenta fotográficamente que con el análisis en vivo es posible identificar a las especies del género Cochlodinium.

Las densidades encontradas en este trabajo (2699 a 8600 cél $\mathrm{mL}^{-1}$ ) se ubican dentro de los valores reportados por otros autores para la zona estudiada (Gárate-Lizárraga et al. 2004, Gárate Lizárraga 2013) y otras regiones como la Bahía de Manzanillo (México) con 3258 cél mL-1 (Morales-Blake et al. 2001), Palawan (Filipinas) con 2613 a 3022 cél mL-1 (Azanza et al. 2008), Sabah (Malasia) con 4160 cél $\mathrm{mL}^{-1}$ (Anton et al. 2008), estuarios de Nueva York (E.U.A.) con $6890 \pm 2980$ cél $\mathrm{mL}^{-1}$ (Gobler et al. 2012) y la Bahía de Santa María (Colombia) con 5000 cél mL-1 (Malagon \& Perdomo 2013). Existen sin embargo, otras localidades como la Bahía de Chesapeake, donde se han registrado valores mayores, llegando a 1 x $10^{4}$ cél $\mathrm{mL}^{-1}$ (Mulholland et al. 2009). Estos mismos autores mencionan que las concentraciones variaron entre 28,1 y 31 x $10^{3}$ cél $\mathrm{mL}^{-1}$ en la desembocadura de los ríos Elizabeth y James, respectivamente, que descargan en esta bahía. Recientemente en las costas de El Salvador también se observaron densidades altas de C. polykrikoides, registrando valores de $215 \times 10^{3}$ cél $\mathrm{mL}^{-1}$ (Espinoza et al. 2013).

Es probable que las altas densidades de células estimadas en nuestro estudio generaran altas concentraciones de oxígeno disuelto $\left(9,1 \mathrm{~mL} \mathrm{~L}^{-1}\right)$ y altas tasas de saturación de oxígeno (> 200). En la Bahía de Chesapeake se registraron valores similares durante un florecimiento de Cochlodinium (Morse et al. 2011), estos autores reportan además que cuando el florecimiento decae, los valores de oxígeno disuelto disminuyen hasta un nivel medio de 2,4 $\mathrm{mL} \mathrm{L}{ }^{-1}$, presumiblemente por la oxidación del material orgánico proveniente de estos dinoflagelados, generando eventos de hipoxia e incluso cercanos a la anoxia. Sin embargo en este trabajo, durante la máxima densidad del florecimiento los valores de oxígeno fueron altos, disminuyendo paulatinamente hasta un nivel medio de $5,5 \mathrm{~mL} \mathrm{~L}^{-1}$, lo que sugiere una frecuente remoción de material orgánico por el flujo y reflujo provocado por corrientes y mareas que se suscitan en la Ensenada de La Paz (Morales \& Cabrera-Muro 1982, Sandoval \& GómezValdés 1997).

La clorofila $a$ y otros pigmentos fotosintéticos como la peridinina son indicadores de biomasa y de la presencia o dominancia de algunos grupos del fitoplancton (Vidussi et al. 1996, Zapata et al. 1998), como es el caso de algunos florecimientos de C. polykrikoides. Es así como Morse et al. (2011) han registrado densidades de 11,129 cél $\mathrm{mL}^{-1} \mathrm{y}$ concentraciones de Clo- $a$ que exceden los $300 \mathrm{mg} \mathrm{m}^{-3}$, también Gobler et al. (2012) reportaron valores altos de Clo- $a\left(25,3\right.$ a 55,7 $\left.\mathrm{mg} \mathrm{m}^{-3}\right)$ asociados a la dominancia de $C$. polykrikoides en los estuarios de Nueva York. En la Bahía de La Paz Gárate-Lizárraga et al. (2004) describieron una alta relación entre el número de células $(360$ x 10³ a 7,05 x 
$10^{6}$ cél $\left.\mathrm{L}^{-1}\right)$, Clo- $a\left(2,7\right.$ a $\left.56,8 \mathrm{mg} \mathrm{m}^{-3}\right)$ y peridinina $(0,68$ a $32,03 \mathrm{mg} \mathrm{m}^{-3}$ ), pigmento característico de dinoflagelados. En este trabajo las concentraciones de Clo- $a$ y peridinina también se relacionaron a la dominancia de $C$. polykrikoides. Bustillos-Guzmán et al. (2004) sugieren que además de la Clo-a como indicador de biomasa durante los florecimientos del fitoplancton, la peridinina puede usarse como huella pigmentaria de dinoflagelados, ellos demuestran que existe una buena correlación entre el número de células y la peridinina $\left(\mathrm{r}^{2}=0,79\right)$ cuando $C$. polykrikoides domina en los florecimientos en la Ensenada de La Paz. En nuestros resultados, la correlación entre la abundancia y la peridinina fue alta, sin embargo la relación de Clo- $a$ y peridinina también fue alta durante todo el evento $\left(r^{2}=0,97\right)$, sugiriendo una dominancia de C. polykrikoides. Adicionalmente, se registraron bajas concentraciones de Clo- $b$ y zeaxantina, probablemente atribuidas a la presencia de flagelados verdes y cianobacterias (Bustillos-Guzmán et al. 1995), organismos que no fueron identificados en este trabajo.

En general los valores de nutrientes en ambas estaciones fueron altos al compararlos con otros trabajos para la misma zona (Bahía de La Paz y Ensenada de La Paz) y periodo (verano-otoño) (Gilmartin \& Revelante 1978, Lechuga-Devéze et al. 1997, Cervantes-Duarte \& Guerrero-Godínez 1988, Cervantes-Duarte et al. 2001). En cuanto a otras localidades, hay similitudes con los resultados de Gobler et al. (2012), sin embargo otros autores han encontrado valores mayores durante los florecimientos de C. polykrikoides (Tomas \& Smayda 2008, Kudela et al. 2008), Gobler et al. (2012) sugieren que este dinoflagelado crece en condiciones moderadas y bajas de nutrientes; luego, es probable que los nutrientes registrados durante las lluvias iniciales, propiciaran condiciones adecuadas para su proliferación. El siguiente evento fuerte de lluvia incrementó la concentración de nutrientes, los cuales fueron asimilados por C. polykrikoides, ocasionando 6 días después el valor máximo del florecimiento. Finalmente la densidad decayó algunos días después, probablemente por la disminución de nutrientes. Es plausible, como lo mencionan GárateLizárraga et al. (2004), que los valores altos de fosfatos tuvieran un rol importante en su proliferación, pues se ha sugerido que los fosfatos pueden regular el crecimiento de C. polykrikoides, incluso más que el nitrato (Park et al. 2001). Referido a esto, Tomas \& Smayda (2008) calcularon valores $\mathrm{N}: \mathrm{P}<10$ durante un crecimiento masivo de esta especie en Pettaquamscutt Cove (Rhode Island, Estados Unidos) y determinaron que la mayor abundancia de células de esta especie ocurre cuando los niveles de fosfatos variaron entre 4 a $6 \mu \mathrm{M}$ y la relación $\mathrm{N}: \mathrm{P}$ fue de 0,1 a 2 . Durante todo el evento registrado en el presente trabajo la relación $\mathrm{N}: \mathrm{P}$ fue $<10$, encontrándose las mayores abundancias celulares cuando la relación $\mathrm{N}: \mathrm{P}$ fluctuó entre 2 y 3, sugiriendo como señalan Tomas \& Smayda (2008), Kudela et al. (2012) y Gobler et al. (2012), que los florecimientos de esta especie se desarrollan en ambientes limitados de nitrógeno ( $\mathrm{N}: \mathrm{P}<15,0)$, o que raramente se establecen en ambientes limitados de fósforo $(\mathrm{N}: \mathrm{P}>15,0)$.

Es altamente factible que el aumento de estos nutrientes inorgánicos haya ocurrido debido al arrastre del agua de lluvia con material terrígeno hacia la costa y la remoción de sedimentos por el viento. Por lo tanto, viento y lluvia contribuyeron en la fertilización de la zona costera de la Ensenada de La Paz, generando condiciones para la proliferación y permanencia de C. polykrikoides o como lo sugiere Kudela et al. (2008), ocupando un nicho abierto para su establecimiento y una probable recurrencia estacional. Sin embargo, se debe considerar que su amplia flexibilidad nutricional, su capacidad de utilizar diferentes fuentes de nitrógeno orgánico e inorgánico, mixotrofía, alelopatía, gran capacidad de migración vertical y la sinergia con otros agentes ambientales (Jeong et al. 2004, Tang \& Gobler 2010, Morse et al. 2011, Gobler et al. 2012) también son factores que contribuyen a su florecimiento.

En este trabajo durante la mayor intensidad del evento, la estimación de los valores de temperatura y salinidad se ubican en el límite más alto registrado en otras partes del mundo durante florecimientos de Cochlodinium sp. (ver Tabla 2, Kudela et al. 2008, 2012) y dentro de los intervalos reportados durante proliferaciones de C. polykrikoides en la parte sur de la Bahía de La Paz (Gárate-Lizárraga et al. 2004, 2009; Gárate-Lizárraga 2013). Es importante mencionar que esta especie se ha encontrado en esta misma bahía, con máximas abundancias de 58,2 y 65 cél $\mathrm{mL}^{-1}$ a temperaturas de 20 y $26^{\circ} \mathrm{C}$ en abril y junio 2006 (Gárate-Lizárraga \& Muñetón-Gómez 2008). Es probable que los intervalos térmicos $\left(20\right.$ a $\left.32^{\circ} \mathrm{C}\right)$ y de salinidad $(35$ a 36) sean los adecuados para esta población, no obstante, se requiere de trabajo experimental para evaluar con mayor precisión los límites de tolerancia y óptimo crecimiento asociados a la temperatura, salinidad, irradiancia y tasas de asimilación de nutrientes.

Finalmente, se concluye que los florecimientos de $C$. polykrikoides en la Bahía de La Paz y Ensenada de La Paz ocurren principalmente en primavera, finales de 
verano y principios de otoño y se asocian a variables como el viento y la lluvia. Ambas contribuyen a la fertilización de la columna de agua, propiciando un ambiente adecuado para el crecimiento de esta especie. Valores relativamente altos de nitrógeno inorgánico, fosfatos y cocientes $\mathrm{N}: \mathrm{P}<3,0$ sugieren que estos organismos proliferan en concentraciones relativamente altas de nitrógeno inorgánico disuelto con respecto a los valores reportados para esta zona, no obstante fueron menores a los fosfatos. La aplicación de fijadores genera incertidumbre en sus conteos, por lo que una estimación, como la que se propone en este trabajo, basada en el contenido celular de peridinina puede apoyar y dar mayor certidumbre a los valores del número de células.

\section{Agradecimientos}

Al Proyecto PC 0.12-CIBNOR, PC 0.11-CIBNOR, SIP 20130942 y CONACyT Ciencia Básica 178227. A Gerardo Rafael Hernández y Saúl Chávez López por la edición de las figuras. Enrique Troyo Diéguez, Álvaro González Michel por el acceso a los datos climatológicos del CIBNOR. A Diana Dorantes por la edición del resumen en inglés. A Iban Murillo, Juan José Ramírez, Enrique Calvillo Espinoza, Jorge Angulo Calvillo y Leyberth Fernández por el apoyo técnico. A los revisores por sus atinadas sugerencias.

\section{LITERATURA CITADA}

Anton A, PL Teoh, SR Mohd-Shaleh \& N MohammadNoor. 2008. First occurrence of Cochlodinium blooms in Sabah, Malaysia. Harmful Algae 7: 331-336.

Azanza RV, LT David, RT Borja, IU Baula \& Y Fukuyo. 2008. An extensive Cochlodinium bloom along the western coast of Palawan, Philippines. Harmful Algae 7: 324-330.

Blackburn SI, CJS Bolch, KA Haskard \& GM Hallegraeff. 2001. Reproductive compatibility among four global populations of the toxic dinoflagellate Gymnodinium catenatum (Dinophyceae). Phycologia 40(1): 78-87.

Bustillos-Guzmán JJ, H Claustre \& JC Marty. 1995. Specific phytoplankton signatures and their relationship to hydrographic conditions in the coastal north-western Mediterranean Sea. Marine Ecology Progress Series 124: 247-258.

Bustillos-Guzmán JJ, I Gárate-Lizárraga, DJ LópezCortés \& F Hernández-Sandoval. 2004. The use of pigment 'fingerprints' in the study of harmful algal blooms. Revista de Biología Tropical 52 (Suppl. 1): 17-26.

Cervantes-Duarte R \& R Guerrero-Godínez. 1988. Variación espacio-temporal de nutrientes de la Ensenada de La Paz, B.C.S. México. Anales del Instituto de Ciencias del Mar y Limnología UNAM 15(2): 129-142.
Cervantes-Duarte R, F Aguirre-Bahena, A Reyes-Salinas \& JE Valdez-Holguín. 2001. Caracterización hidrológica de una laguna costera de Baja California Sur, México. Oceánides 16(2): 93-105.

Dorantes-Aranda JJ, LM García-De La Parra, R AlonsoRodríguez \& L Morquecho. 2009. Hemolytic activity and fatty acids composition in the ichthyotoxic dinoflagellate Cochlodinium polykrikoides isolated from Bahía de La Paz, Gulf of California. Marine Pollution Bulletin 58: 1401-1405.

Dorantes-Aranda JJ, LM García-De La Parra, R AlonsoRodríguez, L Morquecho \& D Voltolina. 2010. Toxic effects of the harmful dinoflgellates Cochlodinium polykrikoides on the spotted rose sanper Lutjanus guttatus. Environmental Toxicology 25(4): 319-326.

Espinoza J, O Amaya, B Reguera, Y Alvarado, G Ruiz \& D Escobar. 2013. A Cochlodinium polykrikoides bloom in El Salvador. Harmful Algae News 23: 13.

Fukuyo Y, H Takano, M Chihara \& K Matsuoka. 1990. Red tide organisms in Japan. An illustrated taxonomic guide, 407 pp. Uchida Rokakuho, Tokyo.

Gárate-Lizárraga I, JJ Bustillos-Guzmán, L Morquecho \& CH Lechuga-Devéze. 2000. First outbreak of Cochlodinium polykrikoides in the Gulf of California. Harmful Algae News 21: 7.

Gárate-Lizárraga I, ML Hernández-Orozco, C BandSchmidt \& G Serrano-Casillas. 2001. Red tides along the coasts of the Baja California Sur, Mexico (1984 to 2001). Oceanides 16: 127-134.

Gárate-Lizárraga I, DJ López-Cortés, JJ BustillosGuzmán \& F Hernández-Sandoval. 2004. Blooms of Cochlodinium polykrikoides (Gymnodiniaceae) in the Gulf of California, México. Revista de Biología Tropical 52(Suppl. 1): 51-58.

Gárate-Lizárraga I \& MS Muñetón-Gómez. 2008. Los riesgos de las mareas rojas en el Pacifico Mexicano. Conversus 3: 20-23.

Gárate-Lizárraga I, CJ Band-Schmidt, F Aguirre-Bahena \& T Grayeb-del Alamo. 2009. A multi-species microalgae bloom in Bahía de La Paz, Gulf of California, México (June 2008). CICIMAR Oceanides 24: 1-15.

Gárate-Lizárraga I. 2013. Bloom of Cochlodinium polykrikoides (Dinophyceae: Gymnodiniales) in Bahía de La Paz, Gulf of California. Marine Pollution Bulletin 67: 217-222.

Gilmartin M \& N Revelante. 1978. The phytoplankton characteristics of the Barries Island Lagoons of the Gulf of California. Estuarine and Coastal Marine Science 7: 20-47.

Gobler CJ, DL Berry, OR Anderson, A Burson, F Koch, BS Rodgers, LK Moore, JA Golesky, B Allam, P Bowers, ZY Tang \& R Nuzzi. 2008. Characterization, dynamics, and ecological impacts of harmful Cochlodinium polykrikoides blooms on eastern Long Island, NY, USA. Harmful Algae 7: 293-307. 
Gobler CJ, A Burson, F Koch, T Tang \& MR Mulholland. 2012. The role of nitrogenous nutrients in the occurrence of harmful algal blooms caused by Cochlodinium polykrikoides in the New York estuaries (USA). Harmful Algae 17: 6474.

Gómez-Villarreal MC, MD Martínez-Gaxiola \& JL PeñaManjarrez. 2008. Proliferaciones algales 2000-2001 en Bahía de Banderas, México según el sensor Sea WiFS. Revista de Biología Tropical 56(4): 1653-1664.

Jeong HJ, YD Yoo, JS Kim, TH Kim, JH Kim, NS Kang \& W Yih. 2004. Mixotrophy in the phototrophic harmful alga Cochlodinium polykrikoides (Dinophycea): Prey species, the effects of prey concentration, and grazing impact. Journal of Eukaryotic Microbiology 51(5): 563-569.

Jiménez-Illescas AR, M Obeso-Nieblas \& DA Salas-de León. 1997. Oceanografía física de la Bahía de La Paz, B.C.S. En: Urbán R \& R Ramírez (eds). La Bahía de La Paz, investigación y conservación, pp. 31-41. UABCSCICIMAR-SCRIPPS, La Paz, Baja California Sur.

Katano T, M Yoshida, J Lee, M Han \& Y Hayami. 2009. Fixation of Chattonella antiqua and C. marina (Raphidophyceae) using Hepes-buffered paraformaldehyde and glutaraldehyde for flow cytometry and light microcopy. Phycologia 48(6): 473-479.

Kim HG, WJ Choi, YG Jung, CS Jung, JS Park, KH An \& CI Park. 1999a. Initiation of Cochlodinium polykrikoides blooms and its environmental characteristics around the Narodo Island in the western part of South Sea of Korea. Bulletin of the National Fisheries Research and Development Institute, Korea 57: 119-129.

Kim CS, SG Lee, CK Lee, HG Kim \& J Jung. 1999b. Reactive oxygen species as causative agents in the ichthyotoxicity of the red tide dinoflagellate Cochlodinium polykrikoides. Journal of Plankton Research 21: 2105-2115.

Kim CS, SG Lee, HG Kim \& JS Lee. 2001. Screening for toxic compounds in the red tide dinoflagellate Cochlodinium polykrikoides: is it toxic plankton? Algae 16: 457-462.

Kim D, T Oda, T Muramatsu, D Kim, Y Matsuyama \& T Honjo. 2002. Possible factors responsible for the toxicity of Cochlodinium polykrikoides, a red tide phytoplankton. Comparative Biochemistry and Physiology Part C: Toxicology \& Pharmacology 132: 415-423.

Kudela RM \& CJ Gobler. 2012. Harmful dinoflagellate blooms caused by Cochlodinium sp.: Global expansion and ecological strategies facilitating bloom formation. Harmful Algae 14: 71-88.

Kudela RM, JP Ryan, MD Blakely, JQ Lane \& TD Peterson. 2008. Linking the physiology and ecology of Cochlodinium to better understand harmful algal bloom events: A comparative approach. Harmful Algae 7: 278-292.

Lechuga-Devéze CH, J García-Pamanes \& J BustillosGuzmán. 1986. Condiciones ecológicas de una laguna costera de la costa oeste del Golfo de California, turbiedad y clorofila $a$. Ciencias Marinas 12(1): 19-31.
Lechuga-Devéze CH, I Murillo-Murillo, F HernándezSandoval \& RA Mendoza-Salgado. 1997. Influencia del drenaje de estanques de cultivo de camarón sobre las características físicas y químicas de las aguas adyacentes. Hidrobiológica 7: 27-32.

Malagon AL \& LV Perdomo. 2013. Cochlodinium polykrikoides bloom in the Colombian Caribbean. Harmful Algae News 47: 14-15.

Mantoura RFC \& D Repeta. 1997. Calibration methods for HPLC. In: Jeffrey SW, RFC Mantoura \& SW Wright (eds). Phytoplankton pigments in oceanography: Guidelines to modern methods, pp. 407-428. UNESCO, Paris.

Margalef R. 1961. Hidrografía y fitoplancton de un área marina de la costa meridional de Puerto Rico. Investigación Pesquera 18: 76-89.

Matsuoka K, A Mizuno, M Iwataki, Y Takano, T Yamatogi, YH Yoon \& J-B Lee. 2010. Seed populations of a harmful unarmored dinoflagellate Cochlodinium polykrikoides Margalef in the East China Sea. Harmful Algae 9: 548-556.

Morales ER \& H Cabrera-Muro. 1982. Aplicación de un modelo numérico unidimensional a la Ensenada de La Paz, B.C.S. Ciencias Marinas 8: 69-89.

Morales-Blake A, C Cavazos-Guerra \& DU HernándezBecerril. 2001. Unusual HABs in Manzanillo Bay, Colima, México. Harmful Algae News 22: 6.

Morse RE, J Shen, JL Blanco-Garcia, WS Hunley, S Fentress, M Wiggins \& MR Mulholland. 2011. Environmental and physical controls on the formation and transport of blooms of the dinoflagellate Cochlodinium polykrikoides Margalef in the Lower Chesapeake Bay and its tributaries. Estuaries and Coasts 34: 1006-1025.

Morse RE, MR Mulholland, WS Hunley, S Fentress, M Wiggins \& JL Blanco-García. 2013. Control on the initiation and development of blooms of the dinoflagellate Cochlodinium polykrikoides Margalef in lower Chesapeake Bay and its tributaries. Harmful Algae 28: 71-82.

Mulholland MR, RE Morse, GE Boneillo, PW Bernhardt, KC Filippino, LA Procise, JL Blanco-Garcia, HG Marshall, TA Egerton, WS Hunley, KA Moore \& DL Berry. 2009. Understanding causes and impacts of the dinoflagellate Cochlodinium polykrikoides, blooms in the Chesapeake Bay. Estuaries and Coasts 32: 734-774.

Nuzzi R. 2004. Cochlodinium polykrikoides in the Peconic Estuary. Harmful Algae News 27: 10-11.

Park JG, MK Jeong, JA Lee, KJ Cho \& OS Kwon. 2001. Diurnal vertical migration of a harmful dinoflagellate Cochlodinium polykrikoides (Dinophyceae), during a red tide in coastal waters of Namhae Island, Korea. Phycologia 40: 292-297.

Parsons TR, Y Maita \& CM Lalli. 1984. A manual of chemical and biological methods for Seawater Analysis, 173 pp. Pergamon Press, Oxford. 
Richlen ML, SL Morton, EA Jamali, A Rajan \& DM Anderson. 2010. The catastrophic 2008-2009 red tide in the Arabian Gulf region, with observations on the identification and phylogeny of the fish-killing dinoflagellate Cochlodinium polykrikoides. Harmful Algae 9: 163-172.

Sandoval FJ \& J Gómez-Valdés. 1997. Tides and tidal currents in Ensenada de la Paz lagoon, Baja California Sur, México. Geofisica Internacional 36(1): 37-47.

Steidinger KA \& K Tangen. 1996. Dinoflagellates. In: Tomas CR (ed). Identifying marine diatoms and dinoflagellates, pp. 387-598. Academic Press, San Diego.

Strickland JDH \& TR Parsons. 1972. A practical handbook of seawater analysis, $310 \mathrm{pp}$. Fisheries Research Board of Canada, Ottawa.

Tang YZ \& CJ Gobler. 2010. Allelopathic effects of Cochlodinium polykrikoides isolates and bloom from the estuaries of long Island, New York, on co-occurring phytoplankton. Marine Ecology Progress Series 404: 19-31.

Tomas CR \& TJ Smayda. 2008. Red tide of Cochlodinium polykrikoides in coastal cove. Harmful Algae 7: 308-317.
Vargas-Montero M, E Freer, R Jiménez-Montealegre \& JC Guzmán. 2004. Extensive blooms due to Cochlodinium polykrikoides: new to Costa Rica. Harmful Algae News 26: 7.

Vargas-Montero M, E Freer, R Jiménez-Montealegre \& JC Guzmán. 2006. Occurrence and predominance of the fish killer Cochlodinium polykrikoides on the Pacific coast of Costa Rica. African Journal of Marine Science 28: 215217.

Vidussi F, H Claustre, J Bustillos-Guzmán, C Cailleau \& JC Marty. 1996. Rapid HPLC method for determination of phytoplankton chemotaxonomic pigments: Separation of chlorophyll $a$ from divinyl-chlorophyll $a$ and zeaxanthin from lutein. Journal of Plankton Research 18: 2377-2382.

Zapata M, J Freire \& JL Garrido. 1998. Pigment composition of several harmful algae as determined by HPLC using pyridine-containing mobile phase polymeric octadecylsilica column. In: Reguera B, J Blanco, ML Fernández \& T Wyatt (eds). Harmful algae, pp. 304-307. Xunta de Galicia y IOCUNESCO, Madrid.

Recibido el 18 de julio de 2013 y aceptado el 7 de marzo de 2014

Editor Asociado: Pilar Muñoz M. 